\title{
NARASI PERJUANGAN KATINI KENDENG DALAM PERSPEKTIF EKOLOGI LIBERATIF AL-QURAN
}

\author{
Wildan Imaduddin Muhammad \\ UIN Syarif HIdayatullah, Indonesia \\ E-mail: wildan.imaduddinmuhammad16@mhs.uinjkt.ac.id
}

\begin{abstract}
The Women Farmer from Mount Kendeng a.k.a Kartini Kendeng are persistence to refuse the operation of cement factories and its mining in their land. They are representative of consevasion movement to not defferred to corporation and goverment for their own land and water. This article illustrates narratively the fighting of Kartini Kendeng trhough the perspective of ecology and liberation in the Quran. It is the convergence of thought from three women scholars are Nur Arfiyah Febriani, Amina Wadud and Asma Barlas. Those women agree that Quran is book of liberation from any oppression and despotism. By viewing the Quran as book of liberation, this research consider that Kartini Kendeng are appropriate with Quranic values. In other word, the religious preaching has been motivates the persistent of Kartini Kendeng.
\end{abstract}

Keywords: Kartini Kendeng; Ecology; Liberation; Quran

Abstrak. Para petani perempuan dari lereng Pegunungan Kendeng atau dikenal dengan Kartini Kendeng sangat gigih menolak operasi Pabrik Semen dan penambangan. Mereka adalah representasi pejuang ekologi yang enggan mengalah dari korporasi yang didukung Negara demi kelestarian tanah dan air. Tulisan ini memotret narasi perjuangan kartini kendeng dengat perspektif ekologi dan liberasi dalam Al-Quran. Perspektif ekologi dan liberasi AlQuran merupakan konvergensi dari pemikiran tiga tokoh: Nur Arfiyah Febriyani, Amina Wadud dan Asma Barlas. Ketiga tokoh ini sepakat bahwa al-Quran adalah kitab pembebasan dari segala bentuk penindasan dan kesewenangan. Dengan memosisikan al-Quran sebagai kitab liberasi, penelitian ini melihat bahwa perjuangan Kartini Kendeng telah sesuai dengan nilai-nilai dalam al-Quran. Salah satu kesimpulan penelitian ini adalah bahwa ajaran agama turut menjadi motivasi perjuangan para Kartini Kendeng.

Kata Kunci: Kartini Kendeng; Ekologi; Liberasi; Al-Quran

Permalink/DOI: https://doi.org/10.15408/harkat.v14i2.12816 


\section{Pendahuluan}

Tepat satu bulan sebelum peringatan hari kartini, 21 Maret 2017, salah seorang pejuang petani dari Pegunungan Kendeng meninggal dunia dini hari pukul 02.30 WIB akibat serangan jantung mendadak dalam perjalanan menuju RS St. Carolus Salemba. Namanya adalah Patmi, ibu dua anak yang rela meninggalkan keluarga demi memperjuangkan tanah tumpah darahnya dari eksploitasi korporasi. Patmi menghembuskan napas terakhir setelah selama empat hari memasung kaki dengan semen di depan Istana Merdeka bersama perempuan lain sebagai simbol perlawanan (Galiartha, 2017).

Patmi (48) dan para perempuan pejuang dari sekitar wilayah pendirian Pabrik Semen diberi gelar Kartini Kendeng demi kegigihan mereka menolak eksploitasi bumi, tanah tempat mereka menggantungkan hidup sehari-hari. Seperti Kartini, para perempuan kendeng mencurahkan segala daya upaya atas tujuan yang diyakini kebenarannya. Karitini berjuang untuk kelestarian pendidikan, sedang perempuan kendeng berjuang demi kelestarian lingkungan dan HAM (Ayoe, 2016).

Aksi yang digelar pada tahun 2017 ini adalah aksi lanjutan setelah sebelumnya para petani Kendeng memenangkan proses hukum di tingkat Mahkamah Agung (MA) atas kasus sengketa izin usaha pertambangan (IUP) dan pendirian pabrik semen dengan tergugat I Gubernur Jawa tengah dan tergugat II PT. Semen Indonesia dengan amar putusan pada tanggal 5 Oktober 2016 (Putusan Mahkamah Agung, 2016). Kemenangan para petani Kendeng yang diwakili oleh Joko Prianto dan Yayasan Wahana Lingkungan Hidup (Walhi) merupakan proses panjang sejak dari PTUN Semarang, PTUN Surabaya, dan sempat ditolak pula oleh MA, hingga akhirnya dikabulkan saat pengajuan kembali di MA (Ihsanuddin, 12 Oktober 2016).
Namun Ganjar Pranowo selaku Gubernur Jawa Tengah mengeluarkan surat baru tertanggal 23 Februari 2017 bernomor 660.1/6 atas izin lingkungan operasional PT. Semen Indonesia (Erdianto, 26 Februari 2017). Akibatnya perjuangan warga di sekitar Pegunungan Kendeng masih terus berlanjut hingga mengorbankan satu pejuang mereka, Patmi (48).

Peringatan hari Kartini tahun ini adalah momentum berharga yang dapat dimaknai dengan perjuangan perempuan Indonesia dalam membela hak-hak mereka. Dalam amatan Komnas Perempuan, telah terjadi pelanggaran hak-hak tersebut selama pendirian dan pengoperasian pabrik semen di kawasan Karst Pengunungan Kendeng (Huda, 22 April 2017).

Kasus Kendeng jika dilihat dari perspektif nilai-nilai dalam al-Quran, maka menarik dan penting untuk dikaji lebih lanjut. Mengingat bahwa isu lingkungan adalah hal serius demi keberlangsungan hidup umat manusia. Dalam Q.S al-Rum [30]: 41, Allah swt berfirman:

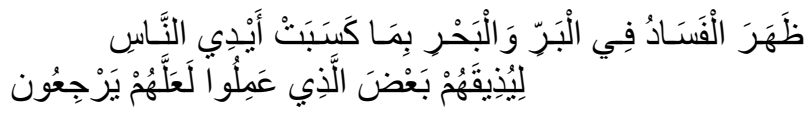

"Telah nyata kerusakan di darat dan di laut disebabkan ulah tangan manusia. Allah menghendaki agar mereka merasakan sebagian dari perbuatan mereka, agar merek kembali (ke jalan yang benar).”

Tahir Ibn Asyur menjelaskan bahwa kata al-fasad bermakna su' al-hal atau buruk perilaku. Artinya bahwa kesalahan perlakuan terhadap alam semesta dampaknya akan kembali pada manusia itu sendiri (Asyur, 1998). Mufassir lain seperti Qurtubi menambahkan tiga makna lain kata al-fasad yakni kekeringan, sedikitnya tumbuh-tumbuhan, dan hilangnya keberkahan. Dengan kata lain bahwa perbuatan manusia yang eksploitatif akan berdampak buruk bagi alam, tempat hidup umat manusia (al-Qurtubi, 1964).

Keterangan tafsir atas ayat di atas dapat dijadikan legitimasi bahwa perusakan 
lingkungan dilarang oleh al-Quran. Hal ini sesuai dengan perjuangan masyarakat kendeng yang menggunakan nilai-nilai spiritual religius sebagai salah satu dasar perjuangan mereka (Pratiwi, 7 April 2017).

Kajian tentang Kendeng telah banyak dilakukan dari berbagai perspektif. Sebagai contoh, Dewi Candraningrum (2015) mengkaji dari sisi ekofeminisme, Mimin Dwi Hartono (2016) dari aspek regulasi, Fahma Wijayanti dkk (2015) lewat kaca mata lingkungan, Endrat Mojo dkk (2015) dengan perspektif kearifan lokal dan Roy Murtadho (2016) melalui pandangan agama Islam. Sebagai peneliti belakangan, penulis melihat bahwa berbagai perspektif tersebut dapat dielaborasi dan memang saling berkait kelindan satu sama lain.

Pertanyaan penelitian yang diajukan antara lain: mengapa Kartini Kendeng begitu gigih melawan operasi Pabrik Semen di wilayah Pegunungan Kendeng? Faktor apa saja yang mendorong semangat mereka? Bagaimana mereka menyikapi pro dan kontra di masyarakat? Bagaimana membingkai kasus Kartini Kendeng lewat perspektif gender alQuran khususnya terkait pemikiran Nur Arfiyah Febriani, Amina Wadud, dan Asma Barlas? Jawaban dari pertanyaan-pertanyaan tersebut sebagian besar telah dijawab oleh para peneliti sebelumnya. Tulisan ini akan fokus pada pertanyaan terakhir dengan tidak menegasikan pertanyaan-pertanyaan lainnya.

Agar lebih jelas dan terukur, diperlukan langkah operasional dan sistematika pembahasan untuk menyelesaikan penelitian ini. Langkah operasional yang akan dilalui antara lain: mengumpulkan data dari berbagai sumber meliputi buku, jurnal, artikel, diagram, dan video wawancara yang diambil dari channel youtube yang terpercaya, memilah setiap data yang dikumpulkan dengan dianalisa satu per satu, mentranskrip video wawancara, mendeskripsikan data-data yang telah dipilih dan dianalisa, dan membaca deskripsi data tersebut lewat perspektif ekologi dan liberasi al-Quran.

Ada lima urutan deskriptif yang akan dijelaskan dalam penelitian ini atau dapat disebut dengan sistematika pembahasan. Pertama, menjelaskan wilayah pegunungan Kendeng Utara dan dampak dilakukannya eksploitasi. Kedua, menarasikan perjuangan Kartini Kendeng dalam membela tanah dan air mereka. Ketiga, menguraikan konsep ekologi alQuran yang diusung Nur Arfiyah Febriani dan dielaborasikan dengan konsep liberasi al-Quran yang ditawarkan Amina Wadud dan Asma Barlas. Keempat, memotret perjuangan Kartini Kendeng dengan perspektif ekologi-liberasi alQuran yang telah dijelaskan sebelumnya. Terakhir adalah penutup.

\section{Sketsa Pegunungan Kendeng Utara dan Dampak Aktivitas Eksploitasi Karst}

Sepertiga wilayah Indonesia adalah batuan kapur dengan luas sekitar 1,4 juta ha. Batuan atau pegunungan kapur ini tersebar di 24 wilayah di tanah air dan diyakini terbentus sejak 470 juta tahun silam (Indonesia, 2016). Kekayaan karst di Indonesia, merupakan jaminan air bersih yang berlimpah dan ketahanan pangan bagi seluruh wilayah. Sayangnya, kekayaan karst ini disalah gunakan. Sehingga mengabaikan fungsi karst sebagai penyeimbang tata kelola air bersih alami. Karst dieksploitasi dan ditambang besar-besaran di berbagai wilayah di Indonesia. Salah satu tempat yang dijadikan tambang adalah daerah Pegunungan Kendeng Utara.

Pegunungan Kendeng Utara memiliki luas wilayah yang memanjang dari Jawa Tengah hingga Jawa Timur meliputi Kabupaten Pati, Rembang, Grobogan, Blora, Tuban, Bojonegoro, dan Lamongan. Empat Kabupaten pertama masuk kawasan Jawa Tengah, sedangkan sisanya temasuk dari wilayah Jawa 
Timur. Pegunungan Kendeng Utara merupakan hamparan perbukitan batu kapur yang telah mengalami proses-proses alamiah selama ribuan tahun lalu. Produk dari dinamika bumi yang berlangsung dari masa lalu hingga saat ini telah menghasilkan suatu fenomena alam yang unik, yang dikenal dengan istilah Bentang Alam Karst. Fenomena Bentang Alam Karst Kendeng Utara tercermin melalui banyaknya bukit-bukit kapur kerucut, munculnya mata air pada rekahan batuan, mengalirnya sungai-sungai bawah tanah dengan lorong gua sebagai koridornya.

Kawasan karst adalah kawasan yang mesti dilindungi. Kawasan karst memiliki fungsi yang sangat penting sebagai penampung air tanah dalam jumlah besar dan sebagai habitat berbagai jenis flora dan fauna. Kawasan karst juga merupakan wilayah yang menjadi kajian para ahli karena menyimpan berbagai fenomena alam yang menarik untuk dikaji dari berbagai disiplin ilmu.

Peraturan Pemerintah No.26 Tahun 2008 tentang Rencana Tata Ruang Wilayah (RTRW) Nasional menegaskan bahwa kawasan karst tergolong dalam kawasan cagar alam geologi karena memiliki keunikan bentang alam. Dengan demikian, kawasan karst adalah kawasan yang harus dilindungi. Pada tahun 2000, dikeluarkan Keputusan Menteri Energi dan Sumber Daya Mineral Nomor 1456 tentang Pedoman Pengelolaan Kawasan Karst yang mengklasifikasikan kawasan karst ke dalam tiga kategori, yaitu kawasan karst kelas I, kawasan karst kelas II dan kawasan karst kelas III. Dengan diberlakukannya Peraturan Pemerintah No. 26 tahun 2008 maka semua batuan karbonat yang mengacu pada Kepmen No.1456 merupakan kawasan lindung.

Karst sendiri merupakan istilah yang digunakan untuk menggambarkan suatu medan berbatuan gamping, mempunyai karakteristik yang unik, dicirikan dengan aliran air di permukaan yang langka, solum tanah yang tipis dan hanya terdapat di area tertentu saja. Terdapat aliran air bawah tanah yang lebih dominan dibanding dengan aliran air yang ada di permukaan. Pembentukan lorong- lorong dan retakan di permukaan menyebabkan air langsung masuk ke dalam sistem aliran bawah tanah sehingga menyebabkan kondisi yang kering di permukaannya (Sudarmadji et al, 2012).

Proses pembangunan pabrik semen yang tengah berlangsung dan terus mendapat penolakan dari berbagai elemen masyarakat, aktivis dan pemerhati lingkungan saat ini, terang menjadi ancaman bagi wilayah Pegunungan Kendeng, secara lebih luas bagi Pulau Jawa. Pabrik yang mempunyai nilai investasi sebesar 3,7 triliun, dengan luas pabrik 103 hektar (ket. PT SI), atau 105 hektar (dok.Amdal), sudah sepantasnya menjadi musuh bersama segenap rakyat Indonesia khususnya Jawa. Pendirian Pabrik Semen tak hanya akan membidik Pegunungan Kendeng Utara, tetapi seluruh Jawa.

Menurut data jaringan advokasi tambang (Jatam), pada tahun 2013 saja izin tambang Karst di Jawa mencapai 76 izin yang terdapat di 23 Kabupaten 42 Kecamatan dan 52 desadengan total konsesi tambang karst 34.944,90 hektar. Kondisi ini bisa menjadi ancaman serius bagi lingkungan di Pulau Jawa.

Kawasan yang akan menjadi ladang tambang dan berdirinya pabrik Semen merupakan kawasan Cekungan Air Tanah (CAT) Watuputih. Berdasarkan hasil pendataan secara berkala yang dilakukan oleh Semarang Caver Association (SCA) dan Jaringan Masyarakat Peduli Pegunungan Kendeng (JMPPK) menyatakan terdapat 44 Ponor, 74 goa yang tersebar di sekitar wilayah CAT Watuputih dan 4 diantaranya merupakan goa yang memiliki sungai bawah tanah aktif. Terdapat 128 mata air yang tersebar di wilayah CAT Watuputih sebagai mata air parenial yang mengalir di sepanjang musim kemarau dan penghujan. 
Air yang dihasilkan dari sumber-mata air yang ada di sekitar kawasan karst CAT Watuputih melebihi kebutuhan dasar masyarakat akan air yang rata-rata membutuhkan 15 - 20 liter/hari/orang. Jika nilai ini dievaluasi sebagai potensi ekonomi, maka jumlah air yang dihasilkan akan melebihi nilai yang didapat dari sektor pertambangan yang justru berpotensi mengurangi bahkan menghilangkan pasokan dan distribusi air pada sumber-mata air yang ada di sekitar kawasan karst CAT Watuputih.

Akibat pertambangan karst di daerah CAT oleh penambang untuk bahan baku semen, sebanyak seratus sembilan mata air terancam hilang, empat puluh sembilan goa tempat bersemayan kelelawar untuk pengendalian hama pertanian dan empat sungai bagi perairan pertanian terancam punah, serta sebanyak 58.368 hektar lahan pertanian terancam terganggu produktivitasnya. Berikut penulis perlihatkan gambar hasil penambangan di Pegunungan Kendeng Utara dan demografi perjuangan warga yang menolak Pabrik Semen dari tahun 2006 sampai sekarang:

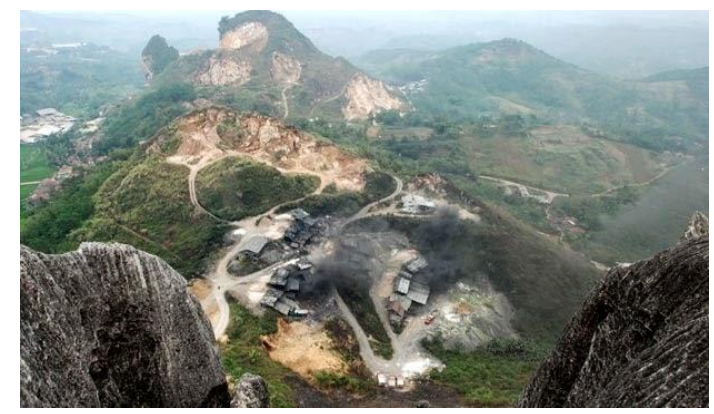

Salah Satu Tempat Penambangan Karst Kendeng Utara Sumber: Google Earth

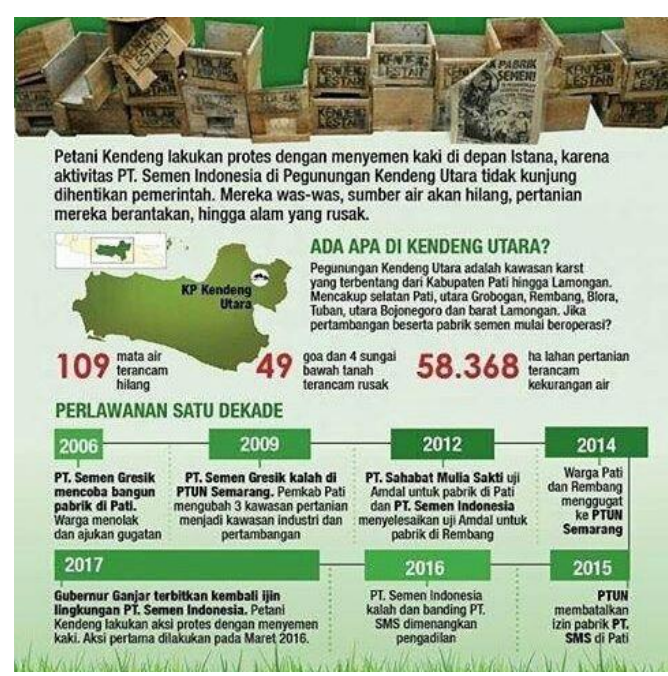

Diagram Konflik Warga, Korporasi, dan Pemerintah dari Tahun 2006 Sumber: Wahana Lingkungan Hidup (Walhi)

Dari dua gambar di atas dapat dilihat bagaimana parahnya kerusakan yang diakibatkan pertambangan Pabrik Semen. Namun demikian, tambang batu gamping atau karst dan juga produksi Pabrik Semen terus dilakukan. Bagian selanjutnya akan dipaparkan narasi perjuangan para Kartini Kendeng dalam menolak eksploitasi wilayahnya yang notabene adalah satu satunya penghidupan mereka.

\section{Narasi Kartini Kendeng dalam Membela Hak Tanah dan Air}

Para penduduk di daerah Pegunungan Kendeng sebagian besar adalah masyarakat Samin. Anggota dari komunitas masyarakat ini dikenal dengan julukan Wong Samin atau Wong Sikep. Dikatakan sebagai Wong Samin karena masyarakat ini merupakan pengikut dari Samin Surosentiko. Dikatakan sebagai Wong Sikep, karena sikap diam mereka yang disertai dengan tindakan mengucilkan diri dari komunitas masyarakat biasa. Sikep berarti isiné sing diakep (isinya yang diambil). Ajaran Samin Surosentiko berkembang ke berbagai daerah baik di daerah Blora maupun di luar Blora. Di antaranya, Bojonegoro, Tuban, Lamongan, Madiun, 
Jember, Banyuwangi, Kudus, Pati, Grobogan, Rembang, Brebes, dan sekitarnya (Burhanudin, Vol. 15, No. 2, 2015).

Samin Surosentiko sendiri adalah nama tokoh yang dijadikan panutan bagi para pengikut ajarannya. Samin Surosentiko lahir pada tahun 1859 dengan nama Raden Kohar Ploso, di desa Kediren, Blora Jawa Tengah. Ia mengubah namanya menjadi Samin karena mengandung makna kesederhanaan. Ajaranajaran Samin masih dipegang teguh oleh para pengikutnya yang kini lebih senang jika dikenal dengan sedulur sikep yang dapat diartikan pula sebagai komunitas keluarga penganut nilai-nilai pokok Samin. Ajaran pokok Samin meliputi kejujuran, kesederhanaan, kerja sama, dan kerja keras (dkk E. M., 2015). Adapun ciri utama dari masyarakat Samin atau sedulur sikep adalah pilihan mereka untuk menggantungkan segala kebutuhan hidup dengan cara bercocok tanam dan beternak.

Keberlangsungan ajaran Samin turut dilestarikan para perempuan penganut ajaran Samin. Dalam arti bahwa perempuan dalam hal ini juga memiliki kontribusi penting di kalangan penganut paham Samin. Gunarti, misalnya, ia perempuan tokoh sedulur singkep yang menjadi pengajar kepibradian Samin bagi anak-anak di kecamatan Sukolilo Kab. Pati (Gunarti, 2016) menuturkan:

..."Yo nek anak-anake sedulur sikep yo sekolah, tapi sekolahe nang mondokane dewe. Sing ngulang yo bapak ibune dewe. Tujuane sekolah yo ora nduwe cita-cita kepengen nggawe derajat pangkat, sekolahe kegayuhane pengen becekno kelakuan karo benerno pangucape. Berarti kan gurune cukup karo bapak ibune. Kanggo kecukupan sandang pangan, yo ora kepengen dadi pegawe, cukupe mergo tetanen, yo gurune cukup bapak ibune.”...

...”Anak-anak sedulur sikep ini sekolah, tetapi sekolahnya di rumah masing-masing. Yang mengajar bapak ibunya sendiri. Tujuan sekolah bukan bercita-cita demi derajat atau pangkat. Tujuan sekolah untuk membenarkan prilaku dan ucapan. Berarti gurunya cukup bapak ibunya. Untuk mencukupi kebutuhan sandang pangan, tidak dengan menjadi pegawai, mendukupkan diri dengan bercocok tanam. Berarti gurunya cukup bapak ibunya sendiri.”...

Saat Pegunungan Kendeng terancam dengan berdirinya Pabrik Semen pada 2006, orang-orang Samin bereaksi. Mereka menolak eksploitasi karst karena membutuhkannya demi memenuhi penghidupan sehari-hari. Para perempuan Samin sepakat untuk menolak dengan gigih. Gunarti menjadi tokoh perempuan yang tak kenal lelah untuk mempertahankan tanah leluhurnya dari eksploitasi. Saat diwawancara itu menuturkan:

..."yang menjadikan kuat dan prihatin itu sebab aku tidak bisa hidup tanpa air. Air itu bagaikan ibuku, tanah itu ibuku. Yang menghidupi sumber mata air itu yang menjadi sumber penghidupanku. Kalau aku merelakan tanah dan air digunakan orang lain untuk dirusak, berarti aku telah merelakan hidupku dan merelakan anak cucuku. Lalu dimana tanggung jawabku selama hidup makan dan minur dari air dan tanah selama puluhan tahun, gratis."...

Kesadaran atas pentingnya tanah dan air serta sikap sederhana yang telah mereka anut selama bertahun-tahun menjadikan mereka tak bisa dibeli oleh apa pun. Para perempuan petani turut andil mempertahankan tanah leluhur mereka dari jerat korporasi Pabrik Semen. Tidak hanya Gunarti, ada beberapa perempuan petani lain yang satu suara dan turut berjuang bersamasama menolak Pabrik Semen. Ada Sugiyem, Sukinah, Sriwianik, Sugiarti, Tatik dan puluhan perempuan lain yang turut andil bersama-sama Guanrti berjuang menolak Pabrik Semen demi kelestarian air dan tanah tempat mereka menggantungkan kehidupan. 
Perempuan-perempuan petani di atas, Sugiyem dan kawan kawan, pernah diwawancarai oleh tim dari Universitas Esa Unggul untuk kepentingan film dokumenter berjudul Pusaka Desaku. Ketika ditanya tentang mengapa menolak Pabrik Semen, misalnya, mereka bersepakat menolak. Masing-masing jawabannya hampir sama, Pabrik Semen bisa merusak kelestarian Pegunungan Kendeng. Berikut cuplikan jawaban mereka pada saat diwawancarai oleh tim dari Esa Unggul yang penulis rangkum dan transkripsikan dari film dokumenter yang diambil dari youtube:

"Kalau uang berapa pun nilainya pasti akan habis, kalau lahan bisa diwariskan ke anak cucu. Kalau kita sudah tidak punya lahan, mau tinggal dimana? Bagi saya tempat tinggal adalah yang terpenting dalam hidup. Lahan pertanian juga bisa untuk diolah, disini lahan pertanian dalam satu tahun sampai tiga kali panen," (Sriwianik, 2016).

"Harapan saya dan kaum tani, mohon tidak mengganggu sumber penghidupan kami, karena kalau petani mogok tanam, bertanam untuk keluarga sendiri, roda pemerintahan tidak akan jalan. Karena kuatnya pemerintahan itu ya dari sandang pangan," (Gunarti, 2016).

"Masyarakat petani disini sudah sejahtera dengan pertanian, tidak perlu ada pabrik semen, saya perwakilan masyarakat dari pegunungan kendeng meminta bapak Gubernur Ganjar Pranowo yang ada di Jawa Tengah, sama bupati Hariyanto yang ada di Pati, dengarkan suara kami rakyat kecil, cabutlah perizinan lingkungan," (Sugiyem, 2016).

"Saya sudah diamanati oleh nenek dan leluhur, kalau bisa justru Pati yang sudah menjadi lumbung padi Jawa Tengah terus berkembang. Sampai kapan pun saya akan menolak. Kita merasa jadi kerepotan akibat adanya pabrik semen. Entah itu mereka, merasa merugikan masyarakat atau tidak. Yang jelas, di desa jadi timbul konflik, karena ada yang pro dan kontra. Yang awalnya damai tentram, jadi saling curiga, berpikiran negatif satu sama lain. Tapi ya semoga saudara kita sendiri mengerti dengan kaum tani," (Tatik, 2016).
Pernyataan-pernyataan yang diungkapkan oleh para perempuan Kendeng menggambarkan sikap tegas dan teguh pendirian. Mereka merasakan sekali dampak sosial dan ekonomi yang diakibatkan Pabrik Semen. Dengan gigih mereka terus melawan lewat aksi-aksi pendirian tenda, demonstrasi, menyemen kaki dan cara cara lain. Semangat yang berapi-api dan tak terpadamkan adalah ciri utama yang dimiliki para perempuan Kendeng demi kelesatarian Ibu Bumi di wilayah mereka. Orasi yang diteriakkan para perempuan kendeng menunjukkan kegigihan mereka, berikut cuplikan yang dipublikasikan KontraS (Komisi untuk orang hilang dan korban tindak kekerasan) (Sukinah, 2015):

$$
\begin{aligned}
& \text { Salam Kendeng! Lestari!!! } \\
& \text { Petani! Makmur!!! } \\
& \text { Jawa Tengah! Jaya!!! }
\end{aligned}
$$

\section{Membaca Perjuangan Kartini Kendeng Perspektif Ekologi-Liberatif Al-Quran}

Ibu Bumi wes Maringi, Ibu Bumi Dilarani, Ibu Bumi Kang Ngadili

\section{Laailaaha illallah Muhammadurrasulullah 2X}

Ibu Bumi wes Maringi, Ibu Bumi Dilarani, Ibu Bumi Kang Ngadili

\section{Laailaaha illallah Muhammadurrasulullah 2X}

Ibu Bumi wes Maringi, Ibu Bumi Dilarani, Ibu Bumi Kang Ngadili

\section{Laailaaha illallah Muhammadurrasulullah 2X}

Penggalan tiga bait di atas adalah doa yang diucapkan masyarakat Samin ketika diundang Najwa Shihab di acara Mata Najwa dengan tema Bergerak Demi Hak yang penulis ambil dari youtube channel Metrotv official yang dipublikasikan pada tanggal 21 Desember 2016. Doa tersebut diucapkan dalam bahasa Jawa yang secara harfiah berarti: ibu bumi sudah memberi, 
ibu bumi disakiti, ibu bumi yang menghukum (Gunretno, 2016).

Adanya dua kalimat syahadat di akhir setiap bait menunjukkan bahwa sedulur sikep memiliki kesadaran beragama yang cukup tinggi. Kalimat syahadat yang menjadi manifestasi keislaman tertinggi dijadikan alat legitimasi bagi mereka. Hal ini juga menafikan pandangan tentang para penganut ajaran Samin yang tidak beragama (Maryono, 2010).

Untuk membaca perjuangan Kartini Kendeng dengan perspektif Ekologi-Liberatif alQuran, perlu dijelaskan terlebih dahulu poinpoin penting pemikiran tiga tokoh yang penulis ambil untuk mensintesakan perspektif tersebut. Perspektif ekologi-liberatif bertujuan untuk memperkokoh legitimasi perjuangan para Kartini Kendeng yang diambil dari nilai semangat pembebasan al-Quran yang turut digelorakan oleh Nur Arfiyah Febriani, Amina Wadud dan Asma Barlas.

Istilah ekologi dan liberasi al-Quran merupakan dua terma berbeda. Diksi pertama, ekologi, penulis ambil dari hipotesa yang dibangun Nur Arfiyah Febriani yang menyebutkan bahwa ajaran universal al-Quran mengajarkan manusia tentang etika lingkungan, untuk menjalankan amanah konservasi alam. Berdasarkan Q.S Rum [30]: 41, Nur Arfiyah menjelaskan selain manusia yang menjadi perusak, manusia juga bertanggung jawab memperbaiki dan melindungi alam semesta (Febriyani, 2016).

Pemikiran ekologi Nur Arfiyah didasarkan pada temuannya tentang isyarat al-Quran mengenai keterkaitan antara ekologi yang mendeskripsikan tentang interkoneksi dan interaksi harmoins antar manusia dengan diri sendiri (habl ma'a nafsih), manusia dengan sesama manusia (habl ma'a ikhwanih) dan manusia dengan alam raya (habl ma'a bi'atih) (Febriyani, 2016). Kemudian ditemukan pula isyarat kesetaraan gender dalam al-Quran tentang ekologi alam: keberpasangan secara biologis, keberpasangan dari segi kualitas dan karakter feminin dan maskulin, dan kata ganti (dhamir) yang menunjukkan pada karakter feminin dan maskulin (Febriani, Vol. 16, No. 2 2015).

Diksi kedua, kata liberasi, penulis ambil dari pemikiran tafsir Amina Wadud dan Asma Barlas, keduanya merupakan pemikir al-Quran perempuan yang berangkat dari semangat melawan tradisi penafsiran patriarkis. Menurut Amina Wadud, ketika menafsirkan al-Quran, penting melalui tiga langkah hermeneutis sebelum menyimpulkan penafsiran: konteks sejarah waktu diturunkannya al-Quran, komposisi gramatikal teks dan keseluruhan weltanschauung atau sudut pandang al-Quran. Dengan basis takwa, dalam pandangan Wadud, manusia tidak dibedakan dari jenis kelaminnya. Karena kata takwa itu sendiri tidak bias gender. Al-Quran dengan konsep takwanya hanya berfokus pada bagaimana fungsi manusia itu dapat secara maksimal berguna bagi sesama manusia (Wadud, Quran and Woman: Rereading the Sacred Text from a Woman Perspective, 1999).

Asma Barlas secara lebih eksplisit menyematkan kata liberasi terhadap penafsiran al-Quran. Berdasarkan refleksinya yang mempertanyakan apakah al-Quran adalah kitab patriarki dan misogini, Asma Barlas kemudian mengkesplorasi sendiri al-Quran dengan perspektif setara gender. Barlas menyimpulkan bahwa memahami al-Quran secara tekstual dapat menghasilkan penafsiran yang bias gender. Oleh karena itu, dalam pandangan Barlas, penting ditekankan dua aspek ketika memahami alQuran: pertama keterbukaan al-Quran yang memungkinkan memahaminya dengan berbagai pemahaman dan kedua tentang pentingnya memahami al-Quran sesuai dengan fakta historis yang mengiringinya (Barlas, 2002). 
Baik Wadud maupun Barlas, sama-sama memiliki kesadaran reflektif tentang problem umat Islam ketika dihadapkan pada problem modernitas yang menuntuk kesetaraan hak antar laki-laki dan perempuan. Dengan pembacaan yang setara gender, mereka berdua sama-sama memiliki kesimpulan bahwa masalah bias gender dalam Islam adalah masalah penafsiran al-Quran yang didominasi laki-laki tanpa ada kesadaran gender di dalamnya.

Dari dua diksi tersebut dikonvergensikanlah menjadi ekologi-liberatif alQuran. Semangat intelektual Nur Arfiyah Febriani, Amina Wadud dan Asma Barlah yang terejawantahkan di ranah akademik memiliki keterkaitan dengan semangat yang digelorakan oleh para Kartini Kendeng di ranah publik. Jika tiga tokoh perempuan tersebut berada di menara gading yang berurusan dengan ide-ide, maka para Kartini Kendeng berada di tataran praktis memperjuangkan kelestarian alam dan hak atas tanah dan air mereka.

Ekologi al-Quran yang menurut Nur Arfiyah mengharuskan umat manusia senantiasa melindungi lingkungan dan melestarikannya telah dipraktikkan oleh perempuan Kendeng. Begitu pun dengan semangat liberasi al-Quran yang dalam tataran wacananya mendorong perempuan untuk turut andil berkontribusi di ranah publik pun telah dijalankan para Kartini Kendeng.

Ekologi-Liberatif al-Quran adalah konsep yang telah dijalankan oleh Kartini Kendeng. Meskipun penulis yakin bahwa Kartini Kendeng tidak secara langsung memahami atau bahkan mengenal konsep tersebut, tetapi mereka dengan penuh kesadaran telah mempraktekkannya demi keutuhan tanah dan air mereka.

\section{Penutup}

Perjuangan Kartini Kendeng dalam perspektif Ekologi-Liberatif al-Quran dipersepsikan sebagai bentuk pengejawantahan nilai-nilai al-Quran dalam tataran praktis. Meskipun mereka tidak mengetahui apa itu konsep Ekologi-Liberatif al-Quran, tetapi arah perjuangan mereka untuk kelestarian ekologi dan semangat pembebasan atas penindasan adalah bentuk riil dari perjuangan yang tidak dapat dijalankan secara langsung oleh para pengusung ide ekologi dan liberasi al-Quran, yang dalam hal ini adalah Nur Arfiyah Febriani, Amina Wadud dan Asma Barlas.

Seperti diperlihatkan dari syair yang dinyanyikan oleh kartini Kendeng dengan menyematkan kalimat syaadat, dorongan keyakinan agama turu andil dalam memperkuat motivasi mereka untuk secara berkesinambungan tanpa kenal lelah memperjuangkan kelestarian Kendeng dan secara berani menuntut hak-hak mereka agar diperhatikan oleh pemerintah.

\section{Daftar Pustaka}

al-Qurtubi, M. S. (1964). Al-Jami' li Ahkam alQuran. Kairo: Dar al-Kutub al-Misriyah.

Asyur, M. T. (1998). Al-Tahrir wa al-Tanwir. Tunisia: al-Dar al-Tunisiy.

Ayoe, D. (2016). Perempuan Pembela HAM: Sembilan Kartini Kendeng. Berita Komnas Perempuan, p. 10.

Barlas, A. (2002). Believing Women in Islam: Unreading Patriarchal Interpretations of the Quran . Austin: University of Texas Press.

Burhanudin, M. d. (2015). Domestifikasi Perempuan Samin dalam Khazanah Islam Modern. Al-Tahrir, Vol. 15, No. 2, 412421.

Erdianto, K. (2017). Pupusnya Harapan Kartini Pegunungan Kendeng. Jakarta: Kompas.

Febriani, N. A. (2015). Wawasan Gender dalam Ekologi Alam dan Manusia Perspektif AlQuran . Ulul Albab, Vol. 16, No. 2. 131153. 
Febriyani, N. A. (2016). Ekologi Berwawasan Gender Dalam Perspektfi al-Quran . Bandung: Mizan.

Galiartha, G. (2017). Satu Kartini Kendeng Berpulang di Perjuangan. Retrieved April 22, 2017, from Berita Antara: http://www.antaranews.com/berita/619380 /satu-kartini-kendeng-berpulang-ditengah-perjuangan

Gunarti. (2016, November 12). Pesan Dari Kendeng. (C. Indonesia, Interviewer)

Gunretno, S. d. (2016, Desember 21). Bergerak Demi Hak. (N. Shihab, Interviewer)

Hartono, M. D. (2016). Perlindungan Hak Atas Air dalam Pembangunan Pabrik Semen di Provinsi Jawa Tengah . Jurnal HAM, Vol. XIII. 1110143.

Huda, L. (2017). Hari Kartini Komnas Perempuan: Perempuan Kendeng Para Pejuang. Jakarta: Tempo.

Ihsanuddin. (2016). Petani Kendeng Menang di MA Lawan PT Semen Indonesia. Jakarta: Kompas.

Indonesia, C. (2016). Pesan dari Kendeng. Pati, Jawa Tengah, Indonesia.

Maryono, D. (2010). Sedulur Sikep: Struktur Sosial dan Agama Masyarakat Samin di Sukalila. Salatiga: UKSW Press.

Mojo, E., dkk, (2015). Saminist's Indegenous Knowledge in Water Conservation in North Kendeng Sukolilo. Komunitas: International Journal of Indonesian Society and Culture, 236-242.
Murtadho, R. (2016). Agama dan Krisi Ekologi: Ketidakmampuan Para Tokoh dan Kiai Melawan Dosa Semen di Rembang. Nizham, 237-253.

Pratiwi, A. M. 2017). Kembalikan Kedaulatan Ruang Hidup dan Ekologi Masyarakat Kendeng Utara . Jakarta: Jurnal Perempuan .

Putusan Mahkamah Agung, 99PK/TUN/2016 (Mahkamah Agung Oktober 5, 2016).

Sriwianik. (2016). Pesan dari Kendeng. (C. Indonesia, Interviewer)

Sugiyem. (2016). Pusaka Desaku. (U. E. Unggul, Interviewer)

Sukinah. (2015). Pesan Kartini Kendeng. (KontraS, Interviewer)

Tatik. (2016). Pusaka Desaku. (U. E. Unggul, Interviewer)

Wadud, A. (1999). Quran and Woman: Rereading the Sacred Text from a Woman Perspective. Oxford : Oxford University Press.

Wadud, A. (2007). Inside the Gender Jihad: Women's Reform in Islam . Oxford: Oneworld.

Wijayanti, F., dkk. (2014). Kajian Potensi Kawasan Karst Kendeng Utara . Rembang: 